\title{
Análise dos Gastos na Alocação dos Recursos Públicos Destinados ao Ensino Fundamental dos Munícipios do Espírito Santo
}

\section{Analysis of Spending on Allocation of Public Funds Intended For Basic Education of The Municipalities Espírito Santo}

\author{
Wellington Dantas Sousa ${ }^{1}$, Matheus Albergaria Magalhães ${ }^{2}$, João Carlos Hipólito Bernardes Nascimento ${ }^{3}$, \\ Juliana Reis Bernardes 4 \\ ${ }^{1}$ Instituto Federal de Educação, Ciência e Tecnologia Baiano, IFBAIANO, Brasil \\ ${ }^{2}$ Fundação Instituto Capixaba de Pesquisas em Contabilidade, Economia e Finanças, FUCAPE, Brasil \\ ${ }^{3}$ Universidade Federal do Rio de Janeiro, UFRJ, Brasil \\ ${ }^{4}$ Universidade Estácio de Sá, UNESA, Brasil \\ Correspondência: Wellington Dantas Sousa. Endereço: Rua do Rouxinol, 115, Imbuí, Salvador, BA CEP \\ 41720052. Tel.: 5571 3186-0001.E-mail: wellington.bmb@hotmail.com
}

Recebido: 13 de outubro de 2016 Aceito: 20 de dezembro de 2016 Publicado: 01 de maio de 2017

DOI: http://dx.doi.org/10.21714/1679-18272016v14n2.p381-392

\begin{abstract}
Resumo
O presente estudo avaliou a eficiência e a eficácia na utilização de recursos públicos aplicados no ensino fundamental dos municípios Capixabas. Por meio de uma pesquisa descritiva, com abordagem predominantemente quantitativa, utilizou-se a Análise Envoltória de Dados - DEA e a técnica de Regressão Logística (Logistic Regression). Os achados revelam que os valores médios gastos por estudante não são determinantes para o alcance das metas estabelecidas pelo IDEB, já que, dentre os 10 municípios que tinham os maiores gastos, apenas metade atingiu a meta do IDEB em sua totalidade e/ou na média. No que tange à eficiência, 16 municípios alcançaram a eficiência máxima na alocação dos recursos, tendo metade deles também atingido a meta do IDEB em sua totalidade e/ou na média. Por fim, relativo à eficácia, foram obtidos indícios da existência de um relacionamento estatisticamente significante entre o IDHM educação, a eficiência na aplicação dos recursos públicos e o alcance da meta do IDEB.
\end{abstract}

Palavras-chave: Educação; Gastos Públicos; IDEB; Eficiência; Eficácia.

\section{Abstract}

This study evaluated the efficiency and effective of use of public funds invested in elementary school of Capixabas municipalities. Through a descriptive study, with predominantly quantitative approach, we used the data envelopment analysis - DEA and the logistic regression technique (Logistic Regression). The findings reveal that the average expenditure per student not is crucial to achieving the targets set by IDEB, since, among the 10 municipalities that had higher expenses, only half reached the goal of IDEB in its entirety and / or the mean. With respect to efficiency, 16 municipalities have reached maximum efficiency in the allocation of resources, taking half of them also reached the IDEB's goal in its entirety and / or the mean. Lastly, on the effectiveness, they were obtained evidence of the existence of a statistically significant relationship between IDHM education, efficient use of public resources and the scope of IDEB goal.

Keywords: Education; Public spending; IDEB; efficiency; Effectiveness.

Esta obra está licenciada sob uma Licença Creative Commons Attribution 3.0.

\section{Introdução}

A educação visa contribuir para que os jovens se preparem para o exercício de uma profíssão durante sua vida, como também integrá-los na sociedade, como cidadãos e membros de uma cultura comum (EL HAJJ, 2011).

Com o objetivo de superar as desigualdades regionais na educação, foi estabelecido o Fundo de Desenvolvimento da Educação Básica e Valorização dos Profissionais da Educação (FUNDEB) que acumula recursos e divide entre os membros federativos, principalmente na base de número de alunos matriculados (SILVA, et al. 2013). O FUNDEB possibilita a alocação de recursos na busca do equilíbrio e de maior igualdade 
na oferta da educação nos municípios (DINIZ; CORRAR, 2011).

O desenvolvimento econômico dos municípios é caracterizado pelo crescimento da renda, acompanhado de melhorias no nível de qualidade de vida da população. As variáveis dos Índices de Desenvolvimento Humano dos Municípios (IDHM) apresentam grande aceitação na literatura como importantes indicadores para avaliação do nível de desenvolvimento de uma localidade. O IDHM é um indicador do nível de atendimento, em uma determinada localidade, das necessidades humanas básicas (OLIVEIRA; SILVA, 2012).

A necessidade de ampliação do acesso à educação e a melhoria da qualidade dos níveis de ensino, bem como mudanças na estrutura de financiamento da educação básica, com inevitáveis impactos de longo prazo para a área, traz à tona a importância da eficiência nos gastos realizados pelo Poder Público para gerar os bens e serviços educacionais, objetivando aferir possíveis dificuldades a serem enfrentadas (RECH; COMUNELO; GODARTH, 2014).

Para que os gastos públicos com educação sejam eficientes, torna-se necessário que o aumento dos gastos seja acompanhado de qualidade, visto que os gastos com educação devem proporcionar a efíciência e a igualdade nos sistemas de ensino, a fim de que o desempenho e o desenvolvimento dos alunos possam se concretizar (BRUNET; BERTÊ; BORGES, 2008).

Nesse aspecto, alguns estudos têm sido conduzidos com o objetivo de avaliar a qualidade do gasto público na educação. Wildert e D'Abreu (2013) avaliaram a eficiência dos gastos públicos com educação fundamental dos municípios alagoanos no período de 2007 a 2011. Diniz, Corrar e Lima (2014) analisaram as relações entre as transferências condicionais e a eficiência dos gastos de municípios brasileiros no ensino fundamental. Já Silva Filho et al. (2014) avaliaram a eficiência na alocação dos gastos públicos com educação no $9^{\circ}$ ano, a série final do ensino fundamental, em 12 unidades de Colégios Militares do Exército no Brasil nos anos de 2009 e 2011.

Entretanto, não foram notados estudos focados em avaliar a eficiência e eficácia dos gastos públicos com o ensino fundamental perante as metas do Índice de Desenvolvimento da Educação Básica - IDEB, em especial dos municípios do Espírito Santo, lacuna essa explorada no presente estudo. Assim, propõe-se a questão que norteia a pesquisa: qual a eficiência e a eficácia na utilização de recursos públicos destinados ao ensino fundamental dos municípios do Espírito Santo? Como objetivo, almeja-se analisar a utilização dos gastos com o ensino fundamental e os resultados dos municípios perante o IDEB.

Para tal, por meio de uma pesquisa descritiva, com abordagem predominantemente quantitativa, utilizou-se a Análise Envoltória de Dados (DEA), modelo BCC, para calcular a eficiência técnica dos municípios e a técnica de Regressão Logística (Logistic Regression) para analisar a eficácia (alcance da meta da nota do IDEB).

Justifica-se a realização do presente estudo pelo fato de que pesquisar acerca da educação contribui para a promoção de mudanças e para o progresso da sociedade (ANDERE; ARAÚJO, 2008). Desse modo, a pesquisa está estruturada em seções, disposta da seguinte forma: além desta introdução, a segunda trata da plataforma teórica que foi estruturada em dois tópicos: Aspectos da Educação e Análise envoltória de dados e estudos relacionados, já a terceira apresenta os aspectos metodológicos do estudo, a quarta compreende a análise e discussão dos dados, e por fim, as considerações finais.

\section{Plataforma Teórica}

\subsection{Aspectos da Educação}

Segundo o art. 205 da Constituição Federal de 1988, a educação é um "direito de todos e dever do Estado e da família[...]". Assim, a educação deve propiciar ao jovem alguns aspectos fundamentais à formação como cidadão, como: fomento à construção de uma consciência crítica, criativa e participativa; formação consistente que permita apreender conteúdos, que motive a análise e interpretação da realidade; e, atrelamento da teoria à prática, contextualizada nos aspectos sócio econômico, político e cultural (EL HAJJ, 2011; GOMES; PINTO; PAULA, 2011).

Para Andere e Araújo (2008, p. 92), a educação "fornece habilidades para utilizar o conhecimento, com condições de refletir, criticar e criar", sendo indispensável para a formação de um cidadão e profissional qualificado. Ainda de acordo com Andere e Araújo (2008), estudar a educação e a qualidade do ensino contribui para a promoção de mudanças e para o progresso da sociedade.

Silva, Souza e Araújo (2013) preconizam que a educação de qualidade pode ser considerada como elemento essencial para que as pessoas melhorem sua condição de vida e possam promover o desenvolvimento do ambiente em que estão inseridas.

No entanto, como bem relacionam Silva Filho et al. (2014), quando comparados com os resultados de outros países, o nível de qualidade da educação do Brasil ainda está abaixo do que se espera de um país em 
desenvolvimento. No ensino superior, por exemplo, segundo o mais recente ranking (2014) do grupo britânico Quacquarelli Symonds (QS), um dos principais organismos de avaliação educacional, o Brasil não possui nenhuma Instituição de Ensino Superior (IES) entre as 100 melhores do mundo. Relativo aos gastos com educação, o Brasil ostenta um dos piores resultados numa recente divulgação internacional com base nos indicadores nacionais divulgados pelo Instituto Nacional de Estudos e Pesquisas Educacionais Anísio Teixeira (INEP), como demonstrado na Figura 1:

Figura 1: Investimento Público Calculado por Estudante: valor aplicado em instituições públicas de todos os níveis educacionais.

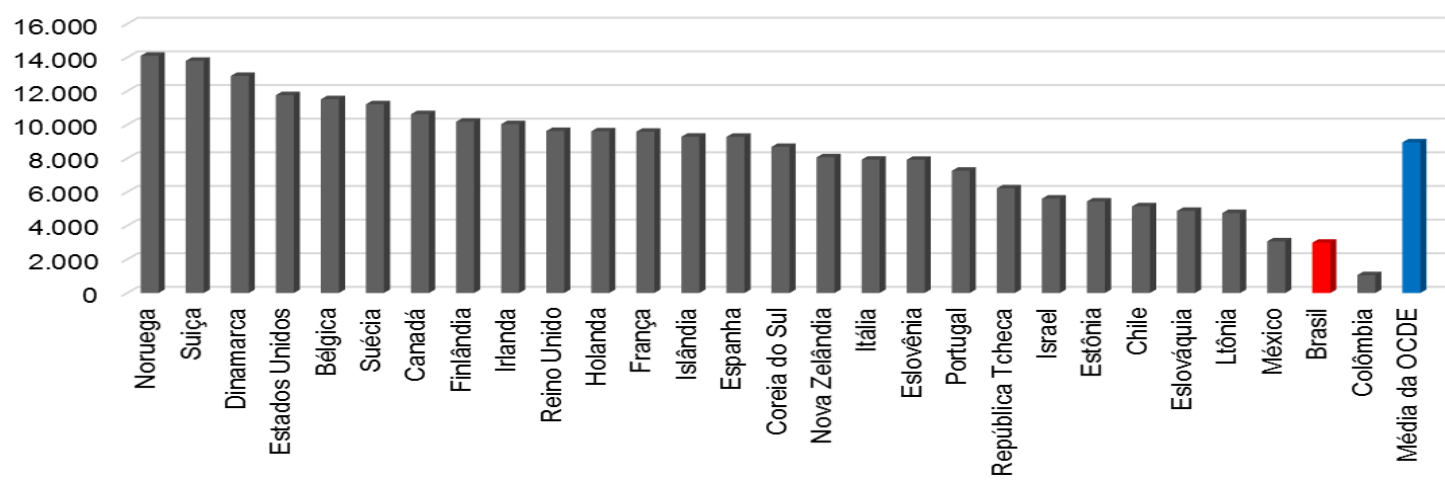

Fonte: elaborado pelo autor com base nos dados do World Education Indicators- WEI, INEP(2014)

Os dados sobre o gasto público em educação fazem parte do relatório divulgado em 2014 e publicado mundialmente pela Organização para a Cooperação Desenvolvimento Econômico - OCDE (INEP, 2014).

Pode-se observar que o Brasil investe em educação cerca de um terço do valor que é investido, em média, pelos países da OCDE, que é o clube das nações mais desenvolvidas do mundo. Enquanto o país gasta US\$ 2.985 , cerca de R $\$ 6.745,00$ por estudante a cada ano, os países da OCDE investem em média US\$ 8.952, aproximadamente $\mathrm{R} \$ 20.230,00$.

A Constituição Federal estabelece, em seu Art. 212, a obrigatoriedade dos municípios, dos estados e da União aplicarem uma porcentagem mínima das receitas advindas de impostos. A união não aplicará menos de $18 \%$; os estados e municípios menos de $25 \%$ de suas receitas de impostos (BRASIL, 1988).

Segundo Mello e Venzon (2014), é preciso evidenciar a qualidade dos gastos públicos, desde que os limites previstos nas legislações não sejam ultrapassados, destacando recursos públicos para a garantia dos direitos sociais preconizados pela Constituição brasileira.

Para Brunet, Bertê e Borges (2008), para que os gastos públicos com educação sejam eficientes, é necessário que o aumento dos gastos seja acompanhado de mais critério e qualidade, visto que melhorias na educação demandam investimentos de longo prazo. Além disso, os gastos com educação devem proporcionar a eficiência e a igualdade nos sistemas de ensino, a fim de que o desempenho e o desenvolvimento dos alunos possam se concretizar.

A educação deve ser acompanhada da qualidade do ensino e garantir a sua eficiência é uma das preocupações recentes da política educacional do país. Na última década, o Brasil conquistou algumas melhorias nos indicadores do seu quadro educacional, como, o aumento da escolaridade média da população, a diminuição da evasão escolar, do trabalho infantil e maior cobertura do ensino fundamental (DELGADO; MACHADO, 2007).

Segundo Rech, Comunelo e Godarth (2014), quando se trata em qualidade na área da educação, tem-se algumas definições, uma delas é 'eficiência', que, por sua vez, pode significar, a virtude ou característica de se conseguir o melhor rendimento com o mínimo de erro e/ou dispêndios de energia, tempo, dinheiro ou meios.

A busca da eficiência está em melhorar a relação resultado/custo, em outras palavras, buscar maximizar resultados (output) e minimizar custos (input) (WILBERT; D'ABREU, 2013). Nesse ponto, surge a necessidade de aprofundar melhor a explanação sobre eficiência e, principalmente, sobre a forma como sua estimação é costumeiramente realizada pela academia.

\subsection{Análise envoltória de dados e estudos relacionados}

A metodologia da Análise de Envoltória de Dados (do inglês Data Envelopment Analysis - DEA) tem como objetivo comparar a eficiência técnica de entidades (unidades), considerando uma série de insumos ou recursos (inputs) utilizados e de produtos (outputs) gerados por uma unidade - no caso específico do presente estudo, uma escola (FARIA; JANNUZZI; SILVA, 2008; LINS, MEZA, 2000). 
http://www.revista.ufpe.br/gestaoorg

A DEA é uma ferramenta matemática utilizada para mensuração da eficiência de unidades produtivas, assim, distinguir eficiência e eficácia é fundamental para entender a aplicabilidade da ferramenta. A eficácia compreende a capacidade de alcançar determinado resultado previamente almejado, logo, o conceito está ligado ao alcance do objetivo, enquanto a eficiência, como visto anteriormente, compreende a relação entre o que foi produzido/alcançado, dado determinada disponibilidade de escassos recursos, e o que poderia ter sido produzido com esses mesmos recursos, assim, o conceito relaciona-se à performance (NASCIMENTO et al., 2013; MELLO et al., 2005).

Portanto, a DEA é uma metodologia não paramétrica que identifica escores de eficiência para cada unidade de produção, por meio de um modelo empírico, em que cada unidade é avaliada em relação às outras unidades de um conjunto homogêneo. Desse modo, as análises da DEA geram uma fronteira de eficiência, em que cada unidade tomadora de decisão (Decision Making Units - DMU) avaliada terá um escore de eficiência entre 0 e 1 ou 0 a $100 \%$ (SILVA, 2009; SILVA et al. 2013).

A DEA, muito utilizada para medir a performance na educação, permite obter a eficiência técnica relativa, partindo de um conjunto de unidades em análise, denominadas DMU's. A DMU é considerada eficiente na geração de seus produtos se conseguirem demonstrar que nenhuma outra unidade ou relação linear consegue produzir maior quantidade de um produto sem diminuir a geração de outro, ou aumentar o consumo de algum insumo. Desta forma, é possível que se faça um ranking que evidencia as DMU's eficientes (NASCIMENTO et al., 2013; BOUGNOL; DULÁ, 2006).

A técnica mensura a eficiência de determinadas DMU's que utilizam insumos iguais (inputs) com o objetivo de obter os melhores resultados (outputs). Uma restrição imposta é que toda DMU se encontre dentro ou na linha da fronteira da eficiência. Portanto, são consideradas eficientes as unidades que se encontrarem na fronteira com o índice de eficiência igual a 1 ou 100\% (NASCIMENTO et al., 2013, SILVA et al. 2013; PEIXOTO et al., 2011; FERREIRA; GOMES, 2009; SILVA, 2009).

O modelo de aplicabilidade da DEA assume duas alternativas: constant returns to scale - CRS (Retornos Constantes de Escala) ou CCR - abreviação dos autores Charnes, Cooper e Rhodese é utilizado quando um aumento no input é sequenciado por um incremento proporcional no output. Relativo ao modelo variable return to scale - VRS (Retornos Variáveis de Escala) também conhecido como BCC, dos autores Banker, Charnes e Cooper que o desenvolveram, é usado quando um aumento de input não é seguido necessariamente por uma adição proporcional no output (NASCIMENTO et al., 2013, SILVA et al. 2013).

Segundo Hass (2003), no modelo BCC as unidades ineficientes são determinadas por meio da comparação desta DMU em relação às outras de mesmo tamanho de operação. Já no modelo CCR as DMU's são comparadas umas com as outras independentes do tamanho na qual cada uma funciona. Ainda de acordo com Hass (2003), pressupõe que no modelo CCR as DMU funcionam em ótima escala (HAAS, 2003).

Para determinar a escolha entre CRS e VRS se faz necessário direcionar a modelagem que será utilizada. É preciso definir se o tratamento dos dados será dirigido aos inputs ou outputs, sendo que o direcionamento aos inputs busca "maximizar as quantidades de produtos, isto é, maximizar uma combinação linear das quantidades dos vários produtos da empresa" (MACEDO; ALMEIDA, 2009, p. 33). Ainda segundo os autores, o direcionamento nos outputs minimiza a quantidade de insumos necessários à produção.

Estudos anteriores têm utilizado a DEA para analisar a eficiência na aplicabilidade de recursos públicos. Silva et al. (2013) mensuraram a eficiência dos municípios mineiros na alocação de recursos públicos para o provimento da educação básica. Os resultados apresentaram uma média das eficiências técnicas de $61 \%$, revelando que $84 \%$ dos municípios podem ser considerados com grau de ineficiência forte ou moderado e menos de $2 \%$ são eficientes.

Savian e Bezerra (2013) buscaram avaliar a eficiência dos gastos públicos com a educação nas séries iniciais do ensino fundamental nos municípios do Estado do Paraná, nos anos de 2005 e 2009. Os municípios foram classificados quanto à eficiência dos gastos em educação fundamental, e foi possível realizar comparações entre os municípios e mesorregiões. Os resultados sugeriram que na maioria dos municípios paranaenses os gastos públicos com educação se mostraram ineficientes, o que demonstra a necessidade de revisão, por parte da administração pública, dos meios de alocação dos recursos.

Wildert e D'Abreu (2013) avaliaram a eficiência dos gastos públicos com educação fundamental dos municípios alagoanos, identificando os municípios mais e menos eficientes no período de 2007 a 2011 . Foram utilizados os dados municipais referentes ao Produto Interno Bruto (PIB), número de habitantes, número de estudantes matriculados, gasto com educação e as notas do IDEB. Os municípios que foram classificados como eficientes foram aqueles com as piores condições de partida, em termos de riqueza média e nível educacional, e que 
gastaram pouco por aluno matriculado. Já os municípios menos eficientes, foram aqueles com a melhor condição de partida em termos de PIB per capita e que apresentaram elevados gastos por aluno, mas que alcançaram os piores desempenhos no IDEB de 2011.

Através de uma investigação acerca da eficiência do gasto público com a educação referente ao ano de 2011 nas cidades do Sudoeste do Paraná, os autores Rech, Comunelo e Godarth (2014) utilizaram como input o gasto aluno e como output a nota dos alunos na Prova Brasil. Os achados da pesquisa evidenciaram que os municípios que possuíam os maiores gastos por aluno, não figuravam nas primeiras posições da eficiência.

Diniz, Corrar e Lima (2014) analisaram as relações entre as transferências condicionais e a eficiência dos gastos de municípios brasileiros no ensino fundamental. Os autores notaram que, de forma geral, as transferências intergovernamentais condicionais direcionadas à educação afetam negativamente a eficiência dos gastos públicos no ensino fundamental. Destaque-se, ainda, que a autonomia financeira tem um efeito positivo na eficiência da educação o que atesta a verificabilidade dos achados da pesquisa.

Silva Filho et al. (2014) desenvolveram um estudo que teve como objetivo avaliar a eficiência na alocação dos gastos públicos com educação no $9^{\circ}$ ano, a série final do ensino fundamental, em 12 unidades de Colégios Militares do Exército no Brasil, sendo tomados como referência de estudo os anos de 2009 e 2011. Através da aplicação da DEA no modelo BCC, os resultados da pesquisa mostraram que para o ano de 2009,58,34\% colégios foram considerados eficientes e para o exercício de 2011 apenas $30 \%$ das unidades.

\section{Aspectos Metodológicos}

A presente pesquisa, quanto à tipologia, caracteriza-se como descritiva e quanto à abordagem do problema predominantemente quantitativa (KUMAR, 2005; GIL,1999). Para operacionalização do estudo, foram utilizadas fontes secundárias de dados coletados durante o mês de dezembro de 2014. Em relação aos dados secundários, a Tabela 01 retrata a descrição das variáveis:

Tabela 1: Descrição das Variáveis

\begin{tabular}{|c|c|c|}
\hline $\begin{array}{l}\text { IDENTIFICAÇÃO } \\
\text { DOS INPUT'S }\end{array}$ & DESCRIÇÃO DOS INPUT'S (INSUMOS) & \begin{tabular}{|c|} 
BASE DA \\
INFORMAÇÃO \\
\end{tabular} \\
\hline $\begin{array}{ll}\text { DeLiq - Despesas } \\
\text { Liquidadas }\end{array}$ & $\begin{array}{l}\text { Trata dos recursos alocados com o Ensino Fundamental } \\
\text { da Educação Básica de cada município. }\end{array}$ & $\begin{array}{l}\text { Sítio do Tesouro Nacional } \\
\text { Brasileiro - STN }\end{array}$ \\
\hline $\begin{array}{l}\text { GaMed - Gasto Médio } \\
\text { por aluno }\end{array}$ & $\begin{array}{l}\text { Refere-se ao gasto médio por aluno matriculado em cada } \\
\text { munícipio. }\end{array}$ & $\begin{array}{l}\text { Resultado da divisão: } \\
\text { Despesas Liquidadas / } \\
\text { Alunos Matriculados }\end{array}$ \\
\hline $\begin{array}{l}\text { DiEdu - IDHM } \\
\text { Dimensão Educação }\end{array}$ & $\begin{array}{l}\text { No Índice de Desenvolvimento Humano dos Municípios- } \\
\text { IDHM, essa dimensão é medida pela escolaridade da } \\
\text { população adulta e pelo fluxo escolar da população } \\
\text { jovem. O índice varia de } 0 \text { a } 1 \text {, quanto mais próximo de } 1 \\
\text { melhor. }\end{array}$ & $\begin{array}{l}\text { Sítio do Programa das } \\
\text { Nações Unidas para o } \\
\text { Desenvolvimento - PNUD }\end{array}$ \\
\hline $\begin{array}{l}\text { DiRen - IDHM } \\
\text { Dimensão Renda }\end{array}$ & $\begin{array}{l}\text { No IDHM, essa dimensão é medida pela renda mensal per } \\
\text { capita. O índice varia de } 0 \text { a } 1 \text {, quanto mais próximo de } 1 \\
\text { melhor. }\end{array}$ & $\begin{array}{l}\text { Sítio do Programa das } \\
\text { Nações Unidas para o } \\
\text { Desenvolvimento - PNUD }\end{array}$ \\
\hline $\begin{array}{l}\text { IDENTIFICAÇÃO } \\
\text { DO OUTPUT }\end{array}$ & SAÍDA: DESCRIÇÃO DO OUTPUT (PRODUTO) & \begin{tabular}{|c|} 
BASE DA \\
INFORMAÇÃO
\end{tabular} \\
\hline $\begin{array}{l}\text { IdebMed - Nota média } \\
\text { do IDEB }\end{array}$ & $\begin{array}{l}\text { Determinou-se a média do Índice de Desenvolvimento da } \\
\text { Educação Básica - IDEB para os municípios (IDEB4 } \\
\text { Série + IDEB8 }{ }^{\mathrm{a}} \text { Série) / } 2\end{array}$ & \begin{tabular}{|lr}
\multicolumn{3}{|l}{ Sítio do Instituto Nacional } \\
de Estudos e & Pesquisas \\
Educacionais & Anísio \\
Teixeira (INEP) &
\end{tabular} \\
\hline
\end{tabular}

Fonte: elaborado pelos autores (2014)

Dados adicionais, como, por exemplo, o número de habitantes previsto para o ano de 2013, foram retirados do sítio do Instituto Brasileiro de Geografia e Estatística - IBGE. Justifica-se a escolha do Estado do Espírito Santo, com população estimada em 3.839.363 habitantes (IBGE, 2013), pelo fato deste encontrar-se em seu $3^{\circ}$ ciclo de desenvolvimento econômico, ostentando atualmente a sétima posição de economia mais competitiva do país (MIRANDA, 2014).

Os munícios que participaram da pesquisa serão apresentados na análise dos dados que se dará por meio da Análise de Envoltória de Dados (do inglês Data Envelopment Analysis - DEA) com aplicação do modelo BCC orientado ao output (saída $=$ Produto/IDEB), com o objetivo de minimizar a quantidade de insumos necessários (entradas = Input's) para se alcançar a média do IDEB (COELLI; RAO; BATTESE, 1998). Em relação às análises da eficiência na utilização dos recursos da educação disponibilizados para aplicação no ensino 
fundamental foram realizadas através do software Frontier Analyst Professional v. 3.2.2®.

\section{Resultados e Discussões}

\subsection{Análise dos Gastos}

O Índice de Desenvolvimento da Educação Básica (IDEB) avalia a evolução da aprendizagem da Educação Básica do país, sendo obtido pelas notas do Sistema Nacional de Avaliação da Educação Básica (Saeb) e pela taxa média de aprovação percentual. A meta para o IDEB de 2022 é alcançar a nota igual a 6,0, que é o patamar educacional da média dos países da organização para a Cooperação e Desenvolvimento Econômico (OCDE) (MINISTÉRIO DA EDUCAÇÃO, 2014).

O IDEB de 2013, divulgado em Setembro de 2014 pelo Ministério da Educação (MEC), apresenta as notas dos anos iniciais do Ensino Fundamental $\left(1^{\circ}\right.$ ao $5^{\circ}$ ano, que compreende a classe de alfabetização até a $4^{\text {a }}$ Série $)$ e dos anos finais do Ensino Fundamental ( $6^{\circ}$ ao $9^{\circ}$ ano, que compreende a $5^{\text {a }}$ até a $8^{\text {a }}$ Série). A Tabela 02 apresenta o resumo dos dados que serviram de base para o teste de eficiência:

Tabela 2: Resumo dos Dados em Ordem Alfabética nos Municípios

\begin{tabular}{|c|c|c|c|c|c|c|c|}
\hline 导 & Município & DeLiq (em R\$) & $\begin{array}{l}\text { Total de } \\
\text { Alunos } \\
\text { matricula } \\
\text { dos }\end{array}$ & $\begin{array}{c}\text { Gasto } \\
\text { médio por } \\
\text { aluno } \\
\text { matriculado } \\
\text { em R\$ }\end{array}$ & $\begin{array}{c}\text { IDHM } \\
\text { Educação }\end{array}$ & $\begin{array}{l}\text { IDHM } \\
\text { renda }\end{array}$ & $\begin{array}{c}\text { IDEB } \\
\text { Média da } \\
\text { até a } 5^{\mathrm{a}} \mathrm{e} \\
\text { até a } 8^{\mathrm{a}} \\
\text { Séries }\end{array}$ \\
\hline 1 & Afonso Cláudio & $16.705 .750,39$ & 2.796 & $5.974,87$ & 0.661 & 0.544 & 4,9 \\
\hline 2 & Águia Branca & $5.107 .883,28$ & 1.175 & $4.347,13$ & 0.660 & 0.595 & 5,0 \\
\hline 3 & Alfredo Chaves & $7.166 .136,16$ & 1.229 & $5.830,87$ & 0.703 & 0.611 & 5,6 \\
\hline 4 & Anchieta & 41.793.197,58 & 3.827 & $10.920,62$ & 0.696 & 0.654 & 4,3 \\
\hline 5 & Apiacá & $3.522 .739,07$ & 816 & $4.317,08$ & 0.659 & 0.549 & 4,9 \\
\hline 6 & Aracruz & $59.230 .306,59$ & 10.048 & $5.894,74$ & 0.717 & 0.707 & 5,2 \\
\hline 7 & Atilio Vivacqua & $7.171 .771,18$ & 1.423 & $5.039,90$ & 0.663 & 0.637 & 4,7 \\
\hline 8 & Baixo Guandu & $12.444 .168,72$ & 2.845 & $4.374,05$ & 0.670 & 0.637 & 4,5 \\
\hline 9 & Barra de S. Francisco & $23.460 .654,88$ & 3.826 & $6.131,90$ & 0.673 & 0.580 & 4,7 \\
\hline 10 & Boa Esperança & $6.739 .951,02$ & 1.411 & $4.776,72$ & 0.651 & 0.590 & 4,4 \\
\hline 11 & Bom Jesus do Norte & $2.624 .336,19$ & 553 & $4.745,64$ & 0.689 & 0.673 & 3,9 \\
\hline 12 & Cachoeiro Itapemirim & $48.479 .115,00$ & 12.549 & $3.863,19$ & 0.733 & 0.677 & 4,5 \\
\hline 13 & Cariacica & $96.916 .888,87$ & 27.283 & $3.552,28$ & 0.699 & 0.628 & 4,1 \\
\hline 14 & Castelo & $13.630 .789,37$ & 4.052 & $3.363,97$ & 0.703 & 0.639 & 5,3 \\
\hline 15 & Colatina & $40.184 .766,86$ & 10.485 & $3.832,60$ & 0.738 & 0.668 & 5,1 \\
\hline 16 & Conceição da Barra & $15.493 .592,30$ & 3.582 & $4.325,40$ & 0.648 & 0.603 & 4,4 \\
\hline 17 & Conceição do Castelo & $5.180 .918,80$ & 1.501 & $3.451,64$ & 0.685 & 0.541 & 5,4 \\
\hline 18 & Domingos Martins & $18.946 .862,31$ & 3.628 & $5.222,40$ & 0.680 & 0.528 & 6,2 \\
\hline 19 & Dores do Rio Preto & $3.695 .591,51$ & 506 & $7.303,54$ & 0.635 & 0.542 & 4,4 \\
\hline 20 & Fundão & $8.879 .498,94$ & 2.224 & $3.992,58$ & 0.708 & 0.623 & 4,1 \\
\hline 21 & Guarapari & $49.593 .252,68$ & 12.786 & $3.878,72$ & 0.746 & 0.626 & 4,1 \\
\hline 22 & Ibatiba & $13.437 .119,89$ & 2.823 & $4.759,87$ & 0.651 & 0.501 & 4,2 \\
\hline 23 & Ibitirama & $7.920 .007,71$ & 1.140 & $6.947,38$ & 0.609 & 0.481 & 4,1 \\
\hline 24 & Iconha & $8.786 .467,03$ & 1.128 & $7.789,42$ & 0.709 & 0.658 & 5,4 \\
\hline 25 & Irupi & $6.570 .286,20$ & 1.238 & $5.307,18$ & 0.658 & 0.493 & 4,4 \\
\hline 26 & Itaguaçu & $6.343 .860,98$ & 1.030 & $6.159,09$ & 0.672 & 0.641 & 5,9 \\
\hline 27 & Itarana & $4.048 .422,73$ & 654 & $6.190,25$ & 0.696 & 0.568 & 5,7 \\
\hline 28 & Iúna & $18.576 .763,24$ & 3.321 & $5.593,73$ & 0.665 & 0.537 & 4,2 \\
\hline 29 & Jaguaré & $16.870 .226,99$ & 3.679 & $4.585,55$ & 0.678 & 0.568 & 4,8 \\
\hline 30 & Jerônimo Monteiro & $4.552 .786,70$ & 826 & $5.511,85$ & 0.685 & 0.589 & 4,9 \\
\hline 31 & João Neiva & $6.862 .377,47$ & 1.796 & $3.820,92$ & 0.751 & 0.663 & 4,7 \\
\hline 32 & Laranja da Terra & $4.084 .224,58$ & 872 & $4.683,74$ & 0.633 & 0.550 & 5,6 \\
\hline 33 & Linhares & $50.153 .226,15$ & 15.415 & $3.253,53$ & 0.721 & 0.630 & 4,8 \\
\hline 34 & Mantenópolis & $8.603 .925,77$ & 1.019 & $8.443,50$ & 0.636 & 0.551 & 5,1 \\
\hline 35 & Marataízes & $18.840 .538,33$ & 4.361 & $4.320,23$ & 0.676 & 0.588 & 4,0 \\
\hline 36 & Marechal Floriano & $8.395 .081,25$ & 1.810 & $4.638,17$ & 0.715 & 0.589 & 5,5 \\
\hline
\end{tabular}


http://www.revista.ufpe.br/gestaoorg

\begin{tabular}{r|l|r|c|c|c|c|c}
\hline 37 & Mimoso do Sul & $8.262 .009,55$ & 1.310 & $6.306,88$ & 0.672 & 0.541 & 3,9 \\
\hline 38 & Montanha & $11.420 .799,01$ & 1.826 & $6.254,54$ & 0.679 & 0.535 & 4,8 \\
\hline 39 & Mucurici & $4.896 .178,74$ & 684 & $7.158,16$ & 0.617 & 0.577 & 4,5 \\
\hline 40 & Nova Venécia & $22.554 .528,84$ & 5.632 & $4.004,71$ & 0.692 & 0.621 & 5,2 \\
\hline 41 & Pancas & $7.096 .746,19$ & 1.555 & $4.563,82$ & 0.648 & 0.562 & 5,2 \\
\hline 42 & Pedro Canário & $8.230 .451,90$ & 2.092 & $3.934,25$ & 0.643 & 0.536 & 4,4 \\
\hline 43 & Pinheiros & $15.655 .216,03$ & 2.939 & $5.326,72$ & 0.668 & 0.558 & 4,5 \\
\hline 44 & Piúma & $11.577 .379,67$ & 2.420 & $4.784,04$ & 0.702 & 0.643 & 4,6 \\
\hline 45 & Ponto Belo & $4.826 .650,06$ & 670 & $7.203,96$ & 0.631 & 0.605 & 4,6 \\
\hline 46 & Santa Teresa & $8.525 .349,04$ & 2.461 & $3.464,18$ & 0.722 & 0.604 & 5,1 \\
\hline 47 & São Gabriel da Palha & $9.875 .330,23$ & 2.853 & $3.461,38$ & 0.739 & 0.578 & 5,0 \\
\hline 48 & São Mateus & $58.301 .347,66$ & 12.426 & $4.691,88$ & 0.719 & 0.655 & 4,9 \\
\hline 49 & São Roque do Canaã & $3.059 .230,13$ & 611 & $5.006,92$ & 0.686 & 0.623 & 4,7 \\
\hline 50 & Serra & $159.684 .625,95$ & 41.314 & $3.865,15$ & 0.720 & 0.664 & 4,1 \\
\hline 51 & Sooretama & $10.410 .966,05$ & 3.289 & $3.165,39$ & 0.650 & 0.556 & 4,0 \\
\hline 52 & Vargem Alta & $11.738 .517,35$ & 2.060 & $5.698,31$ & 0.658 & 0.544 & 5,1 \\
\hline 53 & Venda N. Imigrante & $5.589 .839,04$ & 1.340 & $4.171,52$ & 0.731 & 0.624 & 4,9 \\
\hline 54 & Viana & $33.262 .403,98$ & 7.852 & $4.236,17$ & 0.672 & 0.589 & 4,0 \\
\hline 55 & Vila Pavão & $4.890 .177,52$ & 1.153 & $4.241,26$ & 0.647 & 0.588 & 5,4 \\
\hline 56 & Vila Valério & $3.975 .878,61$ & 1.478 & $2.690,04$ & 0.686 & 0.549 & 5,1 \\
\hline 57 & Vila Velha & $140.792 .991,48$ & 33.911 & $4.151,84$ & 0.807 & 0.734 & 4,5 \\
\hline 58 & Vitória & $168.052 .039,58$ & 26.956 & $6.234,31$ & 0.876 & 0.805 & 4,6 \\
\hline
\end{tabular}

Fonte: dados da pesquisa (2014).

Compõem o estado do Espírito Santo 78 municípios, entretanto, durante a coleta de dados, verificou-se que os municípios Água Doce do Norte, Alegre, Alto Rio Novo, Brejetuba, Divino São Lourenço, Ecoporanga, Governador Lindenberg, Ibiracu, Marilândia, Muniz Freire, Muqui, Presidente Kennedy, Rio Novo do Sul, Santa Leopoldina, Santa Maria de Jetiba, São Domingos do Norte e São José do Calcado, ou seja, 17 municípios, não alcançaram os requisitos para participarem do IDEB ou para terem os seus resultados divulgados pelo INEP, não possuindo, portanto, dados para determinação do produto (output).

Já 03 municípios (Guaçuí, Itapemirim, Rio Bananal) não compuseram a amostra em decorrência da não localização dos dados dos gastos com educação 'despesas liquidadas' no sítio do STN e/ou sítio da Transparência Municipal, nesse caso, não sendo possível a geração dos insumos (input's).

Relativo ao alcance da meta do IDEB, conforme dados disponíveis no sítio do INEP, somente 13 municípios (cerca de $22 \%$ do total da amostra) alcançaram os resultados propostos, tanto para $4^{\mathrm{a}}$ quanto para $8^{\mathrm{a}}$ séries do ensino fundamental, sendo eles: de Águia Branca, Apiaca, Domingos Martins, Itaguacu, Jaguare, Laranja da Terra, Mantenopolis, Mimoso do Sul, Mucurici, Pancas, Pedro Canario, Ponto Belo, Venda Nova do Imigrante. Os demais municípios não atingiram as metas em sua totalidade e/ou atingiram parcialmente (somente $4^{\mathrm{a}}$ ou somente $8^{\mathrm{a}}$ série).

Desse modo, para aplicabilidade do modelo DEA/BCC, determinou-se a média do IDEB para os municípios (IDEB4 ${ }^{\mathrm{a}}$ Série + IDEB8 ${ }^{\mathrm{a}}$ Série) / 2. Na média, o número de municípios que atingiram a meta média do IDEB aumentou para 26 e estão sinalizados em negrito na Tabela 02.

Nota-se, analisando a Tabela 02, que os recursos que foram alocados para Vitória, R $\$ 168.052 .039,58$; Serra, R\$ 159.684.625,95; Vila Velha, R\$ 140.792.991,48; Cariacica, R\$ 96.916.888,87, representam mais de 40\% do total de recursos disponibilizados para os demais municípios ( $\$$ 1.383.692.143,33).

Observa-se ainda que, mesmo tendo mais recursos alocados dentre os 4 principais municípios, Vitória é o que menos apresenta alunos matriculados, 26.956, seguido de Serra, Vila Velha, Cariacica com 41.314, 33.911 e 27.283 alunos matriculados, respectivamente. Mesmo tendo uma alocação significativa de recursos, nenhum desses municípios alcançou, na sua totalidade, a nota do IDEB.

Em contraponto, relativo aos municípios que menos receberam aporte de recursos, tem-se: Bom Jesus do Norte, São Roque do Canaã, Apiacá e Dores do Rio Preto, com R $\$ 2.624 .336,19$, R \$ 3.059.230,13, R\$ 3.522.739,07, $\mathrm{R} \$ 3.695 .591,51$, respectivamente, o que representa menos de $1 \%$ do total aportado pelos 58 municípios. Observa-se, no entanto, que, dos 4 municípios, de fato, 3 têm um número menor de matriculados, Dores do Rio Preto (506 alunos), Bom Jesus do Norte (553 alunos) e São Roque do Canaã (611 alunos). O munícipio de Apiacá que figurava entre os $4 \mathrm{com}$ menos recursos recebidos, recebeu um número de matriculados bem superior aos demais, ou seja, 816 alunos. Destes municípios, somente Apiacá, atingiu as metas do IDEB. 
Quando se observa o custo médio por aluno, os 4 primeiros municípios da relação são: Anchieta (R\$ 10.920,62), Mantenópolis ( $\mathrm{R} \$ 8.443,50)$, Iconha $(\mathrm{R} \$ 7.789,42)$ e Dores do Rio Preto ( $\$$ 7.303,54). Com relação aos 4 últimos, têm-se: Vila Valério, Sooretama, Linhares e Castelo, com gastos médios por aluno na ordem respectiva de $\mathrm{R} \$ 2.690,04, \mathrm{R} \$ 3.165,39, \mathrm{R} \$ 3.253,53, \mathrm{R} \$ 3.363,97$. Dos 4 municípios que apresentam um maior custo por aluno, Mantenópolis alcançou as metas em sua totalidade e Iconha alcançou a meta na média. Os 4 municípios com menor custo por aluno matriculado não atingiram as notas do IDEB, seja em sua totalidade ou na média.

Destaca-se, entretanto, que o Munícipio de Anchieta não atingiu nenhuma meta estipulada pelo IDEB, mesmo possuindo o maior valor médio por aluno matriculado (R\$ 10.920,62). Já os municípios de São Gabriel da Palha e Conceição do Castelo alcançaram, na média, as metas médias do IDEB mesmo tendo ficado entre os últimos em gasto médio por aluno matriculado, respectivamente, $\mathrm{R} \$ 3.461,38$ e $\mathrm{R} \$ 3.451,64$.

Neste aspecto, faz-se necessário avaliar a eficiência dos municípios na utilização dos recursos públicos aportados com a finalidade de oferecer um Ensino Fundamental de qualidade para atingir os objetivos propostos.

\subsection{Análise da eficiência}

Os testes de correlação, significativos a 0,05, entre o "Valor gasto com Ensino Fundamental (desp. Liquidadas)" frente ao "Total de Alunos matriculados" apresentou coeficiente positivo em 0,97, de 0,68 entre o "Valor gasto com Ensino Fundamental (desp. Liquidadas)" frente ao "IDHM Educação" e de 0,64 entre o "Valor gasto com Ensino Fundamental (Despesas Liquidadas)" frente ao "IDHM renda". Os dados da eficiência são apresentados na Tabela 03:

Tabela 3: Eficiência- Ordem Decrescente de Eficiência

\begin{tabular}{|c|c|c|c|c|c|c|c|c|}
\hline $\begin{array}{l}\tilde{\Xi} \\
\frac{0}{0} \\
0\end{array}$ & Município & 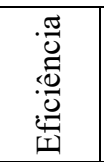 & 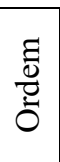 & Município & 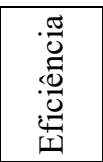 & $\begin{array}{l}E \\
\stackrel{0}{0} \\
\dot{0}\end{array}$ & Município & 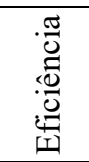 \\
\hline 1 & São Roque do Canaã & 100 & 21 & Ponto Belo & 94,17 & 41 & Conceição da Barra & 79,83 \\
\hline 2 & Dores do Rio Preto & 100 & 22 & Santa Teresa & 94,09 & 42 & Cachoeiro de Itapemirim & 79,66 \\
\hline 3 & Bom Jesus do Norte & 100 & 23 & Pancas & 92,61 & 43 & Piúma & 79,04 \\
\hline 4 & Apiacá & 100 & 24 & Colatina & 91,50 & 44 & Baixo Guandu & 78,01 \\
\hline 5 & Ibatiba & 100 & 25 & Iconha & 91,38 & 45 & Vila Velha & 77,99 \\
\hline 6 & Pedro Canário & 100 & 26 & São Gabriel da Palha & 91,33 & 46 & Boa Esperança & 76,90 \\
\hline 7 & Mucurici & 100 & 27 & Nova Venécia & 91,23 & 47 & Barra de São Francisco & 76,72 \\
\hline 8 & Sooretama & 100 & 28 & Mantenópolis & 90,40 & 48 & Cariacica & 75,13 \\
\hline 9 & Ibitirama & 100 & 29 & Águia Branca & 89,71 & 49 & Pinheiros & 75,04 \\
\hline 10 & Irupi & 100 & 30 & Venda Nova do Imigrante & 89,06 & 50 & Vitória & 74,80 \\
\hline 11 & Itarana & 100 & 31 & Linhares & 89,06 & 51 & Fundão & 73,51 \\
\hline 12 & Vila Valério & 100 & 32 & Vargem Alta & 87,50 & 52 & Serra & 73,38 \\
\hline 13 & Laranja da Terra & 100 & 33 & João Neiva & 85,81 & 53 & Guarapari & 72,41 \\
\hline 14 & Conceição do Castelo & 100 & 34 & Jerônimo Monteiro & 85,5 & 54 & Viana & 70,67 \\
\hline 15 & Itaguaçu & 100 & 35 & Montanha & 84,96 & 55 & Mimoso do Sul & 70,64 \\
\hline 16 & Domingos Martins & 100 & 36 & Aracruz & 84,55 & 56 & Anchieta & 69,92 \\
\hline 17 & Vila Pavão & 98,76 & 37 & São Mateus & 82,63 & 57 & Iúna & 69,65 \\
\hline 18 & Castelo & 98,52 & 38 & Afonso Cláudio & 82,10 & 58 & Marataízes & 68,96 \\
\hline 19 & Marechal Floriano & 96,74 & 39 & Atilio Vivacqua & 81,29 & & & \\
\hline 20 & Alfredo Chaves & 94,80 & 40 & Jaguaré & 81,08 & & & \\
\hline
\end{tabular}

Efetuando uma análise descritiva dos escores de eficiência, notou-se uma média de $87,77 \%$, com coeficiente de variação de 12,12\%, resultados superiores aos obtidos por Silva et al.(2013) para o Estado de Minas Gerais. Considerando que a moda (100) é a medida mais extrema quando comparada à mediana $(89,34)$ e à média $(87,77)$, conclui-se que a eficiência apresenta uma distribuição assimétrica negativa ou à esquerda (assimetria de $-0,265)$, isto é, a maior parte dos municípios apresenta desempenho superior à média. Aproximadamente metade da amostra (28 cidades) apresentou desempenho superior a 90\%, enquanto a nota mínima da amostra foi 
relativamente alta, isto é, 68,96\%.

O valor negativo de curtose $(-1,36)$ indica uma distribuição platicúrtica, ou seja, com observações relativamente dispersas em torno da média. Acerca eficiência máxima, 16 municípios (São Roque do Canaã, Dores do Rio Preto, Bom Jesus do Norte, Apiacá, Ibatiba, Pedro Canário, Mucurici, Sooretama, Ibitirama, Irupi, Itarana, Vila Valério, Laranja da Terra, Conceição do Castelo, Itaguaçu, Domingos Martins) apresentaram tal desempenho, isto é, se localizaram na fronteira de eficiência projetada, com 100\%. Desse seleto grupo, 08 (Apiacá, Pedro Canário, Mucurici, Itarana, Laranja da Terra, Conceição do Castelo, Itaguaçu, Domingos Martins) também atingiram a meta do IDEB.

Esses 16 municípios ostentam um mix ótimo dos inputs que possibilitou um desempenho eficiente quando confrontado com os demais municípios do Estado do Espírito Santo. Acerca dos motivadores para a eficiência técnica, notou-se que todos os municípios eficientes apresentaram valores gastos com ensino fundamental e a quantidade de alunos matriculados em patamares inferiores à média da amostra.

Com um gasto médio por aluno, em média, $15,64 \%$ superior às cidades que compõem a região metropolitana da grande Vitória, as cidades benchmarks obtiveram um resultado médio do IDEB 12,5\% superior. Quando confrontadas com os demais municípios, com um investimento médio por aluno $1 \%$ superior, é notado um incremento na nota IDEB de, aproximadamente, $12 \%$.

Os municípios da metropolitana da grande Vitória apresentaram índices de eficiência bastante comedidos, isto é, ostentando posições próximas do limite inferior de desempenho, a saber: Vila Velha $\left(45^{\mathrm{a}}\right)$; Cariacica $\left(48^{\mathrm{a}}\right)$; Vitória $\left(50^{\mathrm{a}}\right)$; Fundão $\left(51^{\mathrm{a}}\right)$; Serra $\left(52^{\mathrm{a}}\right)$; Guarapari $\left(53^{\mathrm{a}}\right)$; e Viana $\left(54^{\mathrm{a}}\right)$. A exemplo dos achados de Silva et al.(2013), os municípios localizados em regiões com maior desenvolvimento econômico mostraram-se menos eficientes.

\subsection{Análise da eficácia}

Concluída a análise da eficiência via DEA, buscou-se avaliar as determinantes da eficácia (alcance da meta da nota do IDEB) verificando a significância estatística das variáveis utilizadas como inputs (Despesas Liquidadas, Gasto Médio por aluno, IDHM - Dimensão Educação, IDHM - Dimensão Renda e Índice de eficiência) para explicar o alcance da meta da nota do IDEB.

Para tal, utilizou-se a técnica de Regressão Logística (Logistic Regression), método de entrada forçada ou 'Enter', com o alcance da meta assumindo valor 1 e o não cumprimento constante 0. Os resultados do modelo logístico são apresentados na Tabela 04:

Tabela 4: Informações do Modelo Logístico

\begin{tabular}{lrrrrrr} 
& \multicolumn{5}{c}{ Intervalo de Confiança de 95\% para a exp b } \\
\cline { 2 - 7 } & B(EP) & Erro & Wald & Df & \multicolumn{1}{c}{ Sig. } & Exp $(B)$ \\
\hline Incluido & & & & & & \\
Constante & 9,106 & 20,948 &, 189 & 1 &, 664 & 9006,931 \\
Log_Gasto_Ens_Fun & 63,609 & 95,026 &, 448 & 1 &, 503 & $4,218 \mathrm{E}+27$ \\
Log_Alun_Matr & $-64,720$ & 95,263 &, 462 & 1 &, 497 &, 000 \\
Log_GMA & $-63,336$ & 95,300 &, 442 & 1 &, 506 &, 000 \\
IDHMEd & $-33,261$ & 17,530 & 3,600 & 1 &, 058 &, 000 \\
IDHMRe & 4,943 & 9,973 &, 246 & 1 &, 620 & 140,186 \\
Média & 4,040 & 1,258 & 10,318 & 1 &, 001 & 56,801 \\
Eficiência & $-6,899$ & 5,410 & 1,626 & 1 &, 202 &, 001 \\
\hline
\end{tabular}

Fonte: Elaborada pelos autores (2014).

Nota: $R^{2}=0,398$ (Cox \& Snell), 0,533 (Nagelkerke). Estatística Chi-square de 5,817 com significância de 0,668 no Teste de Hosmer e Lemeshow.

O valor de 0,398 no $\mathrm{R}^{2}$ de Cox \& Snell indica que, aproximadamente, $40 \%$ da eficácia da amostra é explicada pelas variáveis independentes inseridas no modelo, enquanto a estatística 0,533 no $\mathrm{R}^{2}$ de Nagelkerke permite concluir que a modelagem explica cerca de $53 \%$ das variações ocorridas no alcance da meta do IDEB. O teste de Hosmer e Lemeshow testa a hipótese nula de que os dados observados são significativamente distintos dos valores previstos pelo modelo, assim, o valor de 5,817 com significância de 0,668 permite concluir que a modelagem prevê bem os valores observados. Essa estatística é corroborada no momento em que o modelo classificou corretamente 79,3\% das observações.

A análise da estatística Wald, que examina se o coeficiente do previsor difere significativamente de zero, permite concluir que as variáveis 'IDHMEd' e a 'média' são significantes ao nível de 0,1 e 0,01 , respectivamente. Os valores superiores a 1 do anti logaritmo - Exp (B) - dos coeficientes 'IDHMEd' e a 'média' permitem concluir 
http://www.revista.ufpe.br/gestaoorg

que o incremento dessas variáveis explicativas acarreta no aumento das chances do município ser eficaz. Em outras palavras, foram obtidos indícios empíricos da existência de um relacionamento estatisticamente significante entre o IDHM educação, a eficiência na aplicação dos recursos públicos e o alcance da meta do IDEB.

Como o IDHM é medido, em grande parte, em função da escolaridade da população adulta, seu relacionamento com o alcance da meta do IDEB pode ser justificado pela influência da escolaridade dos pais na educação dos filhos. Segundo a literatura em literacy (e.g., MOREIRA; GODOY; BASTA, 2003; KIRSCH et al., 2002), o nível educacional dos pais influencia positivamente na educação dos filhos, logo, nos municípios onde existe alto grau de escolaridade da população adulta, existe maior externalidade (influência) dos pais na educação dos filhos.

Acerca do relacionamento entre a eficiência e eficácia, a DMU é considerada eficiente quando, dada determinada restrição de inputs, maximizam o produto (output) de forma a obter os melhores resultados. Nesse aspecto, dada a limitação, por exemplo, do volume gasto com educação básica, o município é eficiente quando maximiza sua nota do IDEB, e eficaz quando o IDEB atinge a meta proposta (eficácia). Em outras palavras, municípios eficientes têm maior propensão a obterem maior nota no IDEB e, consequentemente, a serem eficazes.

\section{Considerações Finais}

Com o intuito de analisar os gastos na utilização de recursos públicos destinados ao ensino fundamental dos municípios do Espírito Santo e os resultados dos municípios perante o IDEB, utilizou-se, neste estudo, a análise descritiva, a Análise Envoltória de Dados (DEA), modelo BCC para estimar a eficiência e a técnica de Regressão Logística (Logistic Regression) para capturar a significância estatística das determinantes da eficácia do alcance da meta do IDEB.

Os resultados dos 58 municípios que fizeram parte do estudo evidenciam que, apesar de os gastos por aluno oscilarem significativamente por município, tendo o município de Anchieta maior gasto médio por aluno matriculado ( $\mathrm{R} \$ 10.920,62$ ) e Vila Valério o menor ( $\mathrm{R} \$ 2.690,04)$, não foi notado fator determinante para se alcançar as metas do IDEB, já que, dentre os 10 municípios que possuem os valores aportados por aluno (gasto médio por estudante), somente metade atingiu a meta do IDEB em sua totalidade e/ou na média (Mantenópolis, Iconha, Ponto Belo, Mucurici e Mimoso do Sul). A outra parte, não alcançou os objetivos (Anchieta, Dores do Rio Preto, Ibitirama, Montanha e Vitória). Prova disso, foram os municípios de São Gabriel da Palha e Conceição do Castelo que alcançaram a meta em sua totalidade e/ou na média mesmo estando entre os últimos municípios com gasto médio por aluno, respectivamente $\mathrm{R} \$ 3.461,38$ e $\mathrm{R} \$ 3.451,64$.

Considerando que a média de gastos por aluno dentre os 58 municípios ficaram na ordem de $\mathrm{R} \$ 5.030,34$, podese considerar que São Gabriel da Palha e Conceição do Castelo fizeram bom uso dos recursos públicos. Ressaltase, ainda que a média brasileira de gastos por aluno, segundo a OCDE, é de cerca de $\mathrm{R} \$ 6.745,00$ por aluno a cada ano.

Analisando a eficiência, o modelo DEA/BCC evidencia que 16 municípios alcançaram a eficiência máxima na alocação dos recursos, ficando em evidencia na fronteira de eficiência projetada, com 100\%, sendo eles: São Roque do Canaã, Dores do Rio Preto, Bom Jesus do Norte, Apiacá, Ibatiba, Pedro Canário, Mucurici, Sooretama, Ibitirama, Irupi, Itarana, Vila Valério, Laranja da Terra, Conceição do Castelo, Itaguaçu, Domingos Martins. Dos municípios eficientes na alocação dos recursos públicos, alcançaram a meta do IDEB em sua totalidade e/ou na média os municípios de Apiacá, Pedro Canário, Mucurici, Itarana, Laranja da Terra, Conceição do Castelo, Itaguaçu, Domingos Martins.

Todos os municípios eficientes apresentaram valores gastos com ensino fundamental e a quantidade de alunos matriculados em patamares inferiores à média da amostra. Um ponto observado foi que os municípios que pertencem à região metropolitana da grande Vitória (Vila Velha, Cariacica, Vitória, Fundão, Serra, Guarapari e Viana) não ostentaram bons desempenhos. No que se refere à eficácia, foram obtidos indícios empíricos da existência de um relacionamento estatisticamente significante entre o IDHM educação, a eficiência na aplicação dos recursos públicos e o alcance da meta do IDEB.

O estudo apresenta limitações no número de municípios pesquisados, uma vez que 20 cidades não puderam fazer parte do estudo. A composição dos municípios, em sua totalidade, potencialmente influencia nos resultados alcançados. Ressalta-se, também, que os achados empíricos restringem-se à amostra compreendida e, como tal, é impossibilitada a generalização dos resultados alcançados.

Sugere-se, desse modo, que futuros estudos contemplem todos os municípios do Espírito Santo, com inputs e outputs que possam abarcar todas as cidades na análise dos dados. Outra oportunidade surge na análise de eficiência, via DEA, em outros estados brasileiros, sobretudo, das regiões Norte e Nordeste, pouco contemplados 
nos estudos anteriores. Por fim, sugere-se a condução de estudos focados em analisar os determinantes da eficácia contemplando outras variáveis explicativas.

\section{Referências}

ANDERE, M. A.; ARAÚJO, A. M. P. Aspectos da formação do professor de ensino superior de Ciências Contábeis: uma análise dos programas de pós-graduação. Revista Contabilidade e Finanças, v. 19, n. 48, p. 91$102,2008$.

BERTÊ, A. M. A.; BORGES, C. B.; BRUNET, J. F. GREGORY. Qualidade do Gasto Público em Educação nas Redes Públicas Estaduais e Municipais. XIII Prêmio Tesouro Nacional, 2008.

BOUGNOL M-L \& DULÁ JH. 2006. Validating DEA as a ranking tool: an application of DEA to assess performance in higher education. Annals of Operations Research, 145(1): 339-365.

BRASIL. Constituição da República Federativa do Brasil (1988). Brasília, DF: Senado Federal.

COELli, T., RAO, D. S. P., BATTESE, G. E.. An Introduction to Efficiency and Productivity Analysis, Klumer Academic Publisher, 1998.

DELGADO, V. MS \& Machado, A. F. (2007). Eficiência das escolas públicas estaduais de Minas Gerais. Pesquisa e Planejamento Econômico, 37(3), p. 427-464.

DINIZ, J. A.; CORRAR, L. J. LIMA, S. C. A Influência das Transferências Condicionais na Eficiência da Educação Fundamental brasileira. VIII Congresso Anpcont, Rio de Janeiro, 2014.

DINIZ, J. A.; CORRAR, L. J. Alocação de recurso públicos na educação fundamental: uma relação entre os gastos e desempenhos dos alunos da rede pública municipal. In.: Congresso da Universidade São Paulo de Controladoria e Contabilidade, XI, 2011, São Paulo - SP. XI Congresso USP de Controladoria e Contabilidade. São Paulo - SP, 2011.

EL HAJJ, Z. S.O Ensino Superior em Ciências Contábeis no Brasil (2000-2009). Anais do II Congresso Nacional de Administração e Ciências Contábeis - AdCont, Rio de Janeiro, 2011.

FARIA, F. P.; JANNUZZI, P. M.; SILVA, S. J. Efficiency of municipal expenditure in health and education: an investigation using data envelopment analysis in the state of Rio de Janeiro, Brazil. Revista da Administração Pública, Rio de Janeiro, v. 42, n. 1, pp.155-177, jan./fev. 2008.

FERREIRA, C. M. C.; GOMES, A. P. Introdução à Análise Envoltória de Dados: Teoria, Modelos e Aplicações. Viçosa: Editora UFV, 2009.

GIL, A. C. Métodos e Técnicas de Pesquisa Social. $5^{\text {a }}$. ed. São Paulo: Atlas, 1999.

GOMES, J. S; PINTO, P.S.B; PAULA, M. M. Metodologia do Ensino: uma análise da percepção dos alunos frente a diferentes formas de ensino. Anais do II Congresso Nacional de Administração e Ciências Contábeis - AdCont, Rio de Janeiro, 2011.

HAAS, D. J. Productivity efficiency of English football teams: A data envelopment analysis approach. Managerial and Decision Economics, v. 24, p. 403 - 410, 2003.

INSTITUTO NACIONAL DE ESTUDOS E PESQUISAS EDUCACIONAIS (INEP). Dados da educação. Disponível em: <http://www.inep.gov.br>. Acesso em: 20 dez. 2014.

INSTITUTO BRASILEIRO DE GEOGRAFIA E ESTATÍSTICA - IBGE. Censo demográfico. Rio de Janeiro, 2014. Disponível em: <http//www.ibge.gov.br>. Acesso em: 26 dez. 2014.

KUMAR, R..Research Methodology - a step-by-step guide for beginners.2nd ed. London: Sage, 2005.

KIRSCH, IRWIN S.; JUNGEBLUT, ANN; JENKINS, LYNN; KOLSTAD, ANDREW. Adult Literacy in America: A First Look at the Findings of the National Adult Literacy Survey. National Center For Education Statistics. U.S., 2002. 201 p.

LINS, M. P. E.; MEZA, L. A. Análise Envoltória de Dados e Perspectivas de Integração no Ambiente de Apoio à Decisão. Rio de Janeiro: COPPE/UFRJ, 2000.

MACEDO, M. A. S.; ALMEIDA, K. Análise do desempenho organizacional no agronegócio brasileiro: aplicando à agroindústria de papel e celulose. Revista de Educação e Pesquisa em Contabilidade (REPeC), Brasília, v. 3, n. 1, art. 2, p. 25-45, jan/abr, 2009.

MELO, J. C. C. B. S.; MEZA, L. A.; GOMES, E. G.; BIONDI NETO, L. Curso de análise de envoltória de dados. XXXVII Simpósio Brasileiro de Pesquisa Operacional - Pesquisa Operacional e o Desenvolvimento 
Sustentável, 27 a 30 de Outubro de 2005, Gramado-RS.

MELLO, G. R.; VENZON, C. Estudo dos Gastos com Saúde, Educação e Pessoal nos Municípios do Sudoeste do Paraná. XIV Congresso USP de Contabilidade e Controladoria. São Paulo, 2014.

MIRANDA, C. L. Centro da Grande Vitória: vitória conexão. Disponível em: $<$ http://www.pucsp.br/artecidade/mg_es/textos/grande_vitoria.pdf > . Acesso em 22 de Dezembro de 2014.

MOREIRA, D. A., GODOY, A. S.; BASTA, C. Educação e Trabalho: Medida do Nível de Alfabetização Funcional em uma Usina Siderúrgica e sua Utilização na Gestão de Pessoas. In: XXVII Encontro da ANPAD. Anais ANPAD. Atibaia: ANPAD, 2003.

NASCIMENTO, J.V.H.B.; NOSSA, V.; BERNARDES, J. R.; SOUSA, W.D. A eficiência dos maiores clubes de futebol brasileiros: evidências de uma análise longitudinal dos últimos 6 anos. XX Congresso Brasileiro de Custos - Uberlândia, MG, Brasil, 2013.

OLIVEIRA, M. J.; SILVA E. A. Eficiência na Gestão Fiscal Pública e o Desenvolvimento Socioeconômico dos Municípios da Microrregião de Cataguases - MG. In

V Encontro de Administração Pública e Governo - EnApg, 2012. Salvador: Associação Nacional dos Programas de Pós Graduação em Administração.

PEIXOTO, F. M.; FERREIRA, R. N.; LOPES, A. L. M.; FAGUNDES, A. F. A. Corporate Governance and Efficiency in the Electricity Sector using Data Envelopment Analysis: a study in the Brazilian stock market. Revista de Ciências da Administração. Florianópolis, v.13, n.31, p. 161-189,Set./Dez. 2011.

PNUD. Programas das Nações Unidas para o Desenvolvimento: pobreza e desigualdade, 2014.Disponível em: <http://www.pnud.org.br>. Acesso em: 28 dez. 2014.

RECH, A. T.; COMUNELO, A. L. GODARTH, K. A. L. Análise da Eficiência dos Gastos Públicos na Educação Fundamental dos Municípios do Sudoeste do Estado do Paraná. EnANPAD: XXXVIII Encontro da ANPAD. Rio de Janeiro, RJ, 2014.

SAVIAN, M. P. G.; BEZERRA, F. M. Efficiency analysis of expenditures with public education in elementary education in the state of Paraná. Economia \& Região, Londrina (Pr),v.1, n.1, p.26-47, jan./jul. 2013

SECRETARIA DO TESOURO NACIONAL. Finanças do Brasil: Estados e Municípios. Disponível em: Www.stn.fazenda.gov.br. Acesso em: 05 dez. 2014.

SILVA, M. C.;SOUZA, F. J. V. ARAÚJO, A. O. Análise da eficiência dos gastos públicos com educação nas capitais brasileiras. Revista Contexto, 13(24), 7-21. 2013.

SILVA, A. A. P. Eficiência na Alocação de Recursos Públicos e Qualidade de Vida nos Municípios Mineiros. 2009. 117 p. Dissertação (Mestrado em Administração) - Universidade Federal de Viçosa - UFV, Viçosa, 2009.

SILVA, C. M. D.; BENEDICTO, G. C.; CARVAlHO, F. M.; SANTOS, A. C. Eficiência na Alocação de Recursos Públicos na Educação Básica em Minas Gerais. EnANPAD: XXXVII Encontro da ANPAD. Rio de Janeiro, RJ, 2013.

SILVA FILHO, G.M.; PEREIRA, T.R.L.; DANTAS, M.G.S.; ARAÚJO, A. O. Análise da eficiência nos gastos públicos com educação fundamental nos colégios militares do exército: evidência para os anos de 2009 e 2011. XIV Congresso USP de Contabilidade e Controladoria. São Paulo, 2014.

WILBERT, M. D., \& D’abreu, E. C. C. F. (2013). Eficiência dos gastos públicos na educação: análise dos municípios do Estado de Alagoas. Advances in Scientific and Applied Accounting, 6(3), 348-372. 